\title{
Relationship between inpatient pressure ulcer prevalence and patient satisfaction levels based on US Medicare's Hospital Compare data
}

\author{
Huey-Ming Tzeng, Hsou Mei Hu and Chang-Yi Yin
}

Accepted for publication: 24 September 2014

\begin{abstract}
Aims
This study examined the relationship between inpatient satisfaction levels and the rates of pressure ulcers (PUs) developing or worsening during hospital stays among Medicare inpatients. The inpatient satisfaction scales, as part of the Hospital Care Quality Information from the Consumer Perspective (HCAHPS), are conceptualised as a proxy for hospital-based patient-centred interventions. This study was developed based on Donabedian's (1986) structure-process-outcome triad framework and the study conducted by Boulding et al. (2011) that showed HCAHPS measures could play an important role in the evaluation of hospital performance in relation to readmissions.
\end{abstract}

\section{Background}

The U.S. National Strategy for Quality Improvement in Health Care (US Department of Health \& Human Services 2013) emphasises making patient care safer by reducing harm associated with care delivery. PU is one of 27 targeted hospital-acquired conditions (HACs), and the goal is to reduce preventable HACs by $40 \%$ by the end of 2014 . The national average rate for severe PUs that occurred during hospital stays is 0.14 based on 2011 data [Centers for Medicare \& Medicaid Services (CMS) 2013a]. Identifying hospital-level patient-centred measures that are accessible to the public and associated with the PU rates is desperately needed.

Authors: Huey-Ming Tzeng, PhD, RN, FAAN, Professor of Nursing and Associate Dean, College of Nursing, Washington State University, Spokane, WA; Hsou Mei Hu, PhD, MBA, MHS, Lead Analyst, Office of Clinical Affairs, University of Michigan, Ann Arbor, MI, USA; Chang-Yi Yin, MA, Professor, Department of History, Chinese Culture University, Taipei, Taiwan

\section{Design}

This exploratory, cross-sectional study used two publicly available national data sets: the HCAHPS and PU rates from the Hospital Compare website and the American Hospital Association (AHA) Annual Survey data set. Both data sources were from 2011, and they were merged into a single data set based on each hospital's Medicare Provider ID. The unit of analysis was the hospital. This study was approved by the Institutional Review Board of the first author's employed university.

\section{Methods}

\section{Sample}

This study included general acute care hospitals that were members of the AHA and had submitted HCAHPS measures to CMS in 2011. Another inclusion criterion was that at least $10 \%$ of the hospitals' total inpatient admissions were Medicare patients in 2011. This criterion was used because the PU rates were calculated based on Medicare discharges. A total of 3203 USA hospitals met the inclusion criteria and were included in the analyses.

\section{Data sources}

CMS-HCAHPS

The HCAHPS survey contained 18 patient perspectives on care during their acute care hospital experience. The hospi-

Correspondence: Huey-Ming Tzeng, Professor of Nursing and Associate Dean, College of Nursing, Washington State University, Spokane, WA 99210-1495, USA. Telephone: +1 7343580358.

E-mail: tzenghm@gmail.com 
tal-level results are publicly reported on the Hospital Compare website four times a year. The survey is administered 48 hours to six weeks after discharge to a random sample of adult patients across medical conditions (not limited to Medicare beneficiaries) throughout each month of the year. To ensure that data are collected properly, CMS undertakes a series of quality oversight activities. The Hospital Compare site reports 10 HCAHPS measures including six scales, two individual items and two global ratings. Each of the six scales consists of two or three items from the survey and is reported as a single scale. For example, the scale of communication with nurses had three items that were rated using four-point scales: 1 = never, 4 = always. The percentages of patients who gave a rating of four were used for calculating the measures. A $100 \%$ level would mean that patients were always satisfied (CMS 2013b).

Seven measures were included in the analysis because they were process-oriented, concerning patients' care experience during hospital stays. These measures were staff responsiveness, hospital cleanliness, hospital quietness at night, physicians' communication, nurses' communication, pain management and explanation about medicines before administration. The three remaining measures, concerning discharge information, overall rating of hospital and willingness to recommend the hospital, were excluded from the analysis (CMS 2013b).

\section{CMS-PUs}

CMS annually calculates the HAC measures based on claims and administrative data as well as present-on-admission coding on the Medicare fee-for-service discharges. CMS first posted hospital-specific HAC data on the Hospital Compare site in October 2011. The 2011 data were updated in July 19, 2012; the Medicare PU stages III and IV HAC rates were calculated by CMS based on the claim and administrative data from July 1, 2009-June 30, 2011. The HAC data have not been updated since July 2012. The PU rate per 1000 Medicare fee-for-service discharges was defined as (the number of Medicare PU stages III and IV HAC cases/the total number of Medicare fee-forservice discharges) $\times 1000$ (CMS 2013a).

\section{Statistical analysis}

Data were summarised using means, standard deviations (SD) and ranges (minimum to maximum). The association between the PU stages III and IV HAC rates and patient satisfaction measures were examined through Pearson correlation analyses. All significance testing was done at the 0.05 level. SPSS version 21.0 Windows (Chicago, IL, USA) was used.
Table 1 Descriptive analyses for the studied variables $(n=3203)$

\begin{tabular}{lrrc}
\hline Variableldescriptive information & Mean & SD & Range \\
\hline $\begin{array}{l}\text { Pressure ulcer rate per 1000 Medicare } \\
\text { fee-for-service discharges }\end{array}$ & 0.11 & 0.24 & $0-4 \cdot 30$ \\
\% Inpatient satisfaction with & & & \\
$\quad$ Staff responsiveness & 63.93 & 8.24 & $30-98$ \\
Nurses' communication & 76.55 & 5.52 & $48-99$ \\
Cleanliness of the environment & $70 \cdot 95$ & 6.84 & $43-98$ \\
Pain management & 69.50 & $5 \cdot 23$ & $39-98$ \\
Explanation of medicines & 61.22 & 5.99 & $29-97$ \\
Quietness at night & 58.51 & 10.36 & $30-93$ \\
Physicians' communication & 80.13 & 5.08 & $56-100$ \\
\hline
\end{tabular}

The order of the seven inpatient satisfaction measures is based on the strength of the correlation coefficients with the pressure ulcer rates.

\section{Results}

Descriptive analyses are summarised in Table 1. Thirty-five per cent of the included hospitals had at least one Medicare patient with a PU stage III or IV HAC. The Pearson correlation analyses showed that higher PU rates were associated with lower inpatient satisfaction levels with staff responsiveness $(r=-0.202, \quad p<0.001)$, hospital cleanliness $(r=-0.170, p<0.001)$, hospital quietness at night $(r=$ $-0.131, \quad p<0.001)$, physicians' communication $(r=$ $-0.122, p<0.001)$, nurses' communication $(r=-0.179$, $p<0.001)$, pain management $(r=-0.165, p<0.001)$ and explanation about medicines before administration $(r=-0.148, p<0.001)$.

\section{Conclusion}

Higher PU rates were found to be significantly correlated with lower inpatient satisfaction levels. Inpatient satisfaction levels with staff responsiveness and with nurses' communication were the two strongest factors associated with lower PU rates. The main limitation of this study was the inability to establish a cause-effect relationship. The studied variables were limited to the ones available in the public domain. Another study limitation was that hospital-level data were used because the available information was not broken down by speciality area.

\section{Relevance to clinical practice}

PU prevalence is confirmed to be a nursing-sensitive inpatient outcome indictor. Nursing staff play a critical role in preventing HAC PUs. To effectively allocate constrained 
personnel resources to prevent HAC PUs, nursing executives and leaders could regularly monitor PU rates in conjunction with inpatient satisfaction levels with staff responsiveness and nurses' communication.

\section{Disclosure}

The authors have confirmed that all authors meet the ICMJE criteria for authorship credit (www.icmje.org/ethical_1author.html), as follows: (1) substantial contributions to conception and design of, or acquisition of data or analysis and interpretation of data, (2) drafting the article or revising it critically for important intellectual content and (3) final approval of the version to be published.

\section{Funding}

Not applicable.

\section{Key words}

consumer satisfaction, hospitals, patient harm, patient safety, patient satisfaction, patients, pressure ulcer

\section{Conflict of interest}

The authors declare that they have no conflict of interest, including financial, consultant, institutional and other relationships that might lead to bias or a conflict of interest.

\section{References}

Boulding W, Glickman SW, Manary MP, Schulman KA \& Staelin R (2011) Relationship between patient satisfaction with inpatient care and hospital readmission within 30 days. The American Journal of Managed Care $17,41-48$.

Centers for Medicare \& Medicaid Services (CMS) (2013a) Hospital Compare. Available at: http://www.cms.gov/Medi care/Quality-Initiatives-Patient-Assess
ment-Instruments/HospitalQualityInits/ HospitalCompare.html (accessed 20 June 2014).

Centers for Medicare \& Medicaid Services (CMS) (2013b) Medicare.gov: Patients' Survey. Available at: http://www.medi care.gov/HospitalCompare/Data/Patient Survey/Overview.aspx (accessed 1 June 2014).

Donabedian A (1986) Criteria and standards for quality assessment and monitoring. QRB. Quality Review Bulletin 12, 99-108.

US Department of Health and Human Services (2013) 2013 Annual Progress Report to Congress: National Strategy for Quality Improvement in Health Care. Washington, DC: US Department of Health and Human Services. Available at: http://www.ahrq.gov/ workingforquality/nqs/nqs2013annlrpt. pdf (accessed 1 June 2014).

The Journal of Clinical Nursing (JCN) is an international, peer reviewed journal that aims to promote a high standard of clinically related scholarship which supports the practice and discipline of nursing.

For further information and full author guidelines, please visit JCN on the Wiley Online Library website: http:// wileyonlinelibrary.com/journal/jocn

\section{Reasons to submit your paper to JCN:}

High-impact forum: one of the world's most cited nursing journals, with an impact factor of 1.316 - ranked 21/101 (Nursing (Social Science)) and 25/103 Nursing (Science) in the 2012 Journal Citation Reports ${ }^{\circledR}$ (Thomson Reuters, 2012).

One of the most read nursing journals in the world: over 1.9 million full text accesses in 2011 and accessible in over 8000 libraries worldwide (including over 3500 in developing countries with free or low cost access).

Early View: fully citable online publication ahead of inclusion in an issue.

Fast and easy online submission: online submission at http://mc.manuscriptcentral.com/jcnur.

Positive publishing experience: rapid double-blind peer review with constructive feedback.

Online Open: the option to make your article freely and openly accessible to non-subscribers upon publication in Wiley Online Library, as well as the option to deposit the article in your preferred archive. 